\title{
The Dose-Response Relationship Between Body Mass Index and Mortality in Subjects Admitted to the ICU With and Without Mechanical Ventilation
}

\author{
Yusuke Sasabuchi MD, Hideo Yasunaga MD PhD, Hiroki Matsui MPH, Alan T Lefor MD MPH, \\ Hiromasa Horiguchi PhD, Kiyohide Fushimi MD PhD, and Masamitsu Sanui MD PhD
}

\begin{abstract}
BACKGROUND: Obesity has been associated with increased mortality in the general population, whereas a paradoxical relationship between higher body mass index and lower mortality has been referred to as the obesity paradox in critically ill patients. However, it remains unknown whether a particular subgroup is most affected. The aim of the present study is to elucidate whether obesity is associated with lower mortality in the ICU population by comparing subjects with and without mechanical ventilation. METHODS: A total of 334,238 subjects from a nationwide database who were discharged between July 2010 and March 2012 and who were admitted to general ICUs during their hospitalization were included in this study. The primary outcome was in-hospital mortality. RESULTS: Of all subjects evaluated, $23.3 \%$ were started on mechanical ventilation within the first $2 \mathrm{~d}$ after ICU admission. Compared with the non-ventilated group, the ventilated group was more likely to have sepsis, pneumonia, or coma. The ventilated group underwent more procedures within the first $2 \mathrm{~d}$ after ICU admission compared with the non-ventilated group. A restricted cubic spline function showed lower mortality in subjects with a higher body mass index among the ventilated group, whereas mortality was increased with increasing body mass index in the non-ventilated group. CONCLUSIONS: This study shows that a high body mass index is associated with low mortality in the mechanically ventilated group, whereas the non-ventilated group showed a reverse $\mathrm{J}$-shaped association. There was a higher mortality rate in underweight subjects in both groups. Key words: body mass index; ICU; mechanical ventilation; obesity; obesity paradox; restricted cubic spline. [Respir Care 2015;60(7):983-991. (C) 2015 Daedalus Enterprises]
\end{abstract}

\section{Introduction}

Obesity is a serious health problem worldwide, ${ }^{1}$ and is associated with a significantly increased risk for develop-

Drs Sasabuchi, Yasunaga, and Matsui are affiliated with the Department of Clinical Epidemiology and Health Economics, School of Public Health, University of Tokyo, Tokyo; Dr Lefor is affiliated with the Department of Surgery, Jichi Medical University, Tochigi; Dr Horiguchi is affiliated with the Department of Clinical Data Management and Research, Clinical Research Center, National Hospital Organization Headquarters, Tokyo; Dr Fushimi is affiliated with the Department of Health Policy and Informatics, Tokyo Medical and Dental University Graduate School of Medicine, Tokyo; Dr Sanui is affiliated with the Department of Anesthesiology and Critical Care Medicine, Jichi Medical University Saitama Medical Center, Saitama, Japan.

This study was supported by Research on Policy Planning and Evaluation grant No. H25-Policy-010 from the Ministry of Health, Labour and Wel- ment of hypertension, diabetes mellitus, heart disease, stroke, and certain malignancies ${ }^{2-5}$ in the general population. As obesity in the general population is epidemic, the

\footnotetext{
fare, Japan and by Funding Program for World-Leading Innovative R\&D on Science and Technology (FIRST) grant No. 0301002001001 from the Council for Science and Technology Policy, Japan. The authors have declared no other conflicts of interest.

Correspondence: Hideo Yasunaga MD PhD, Department of Clinical Epidemiology and Health Economics, School of Public Health, University of Tokyo, 7-3-1, Hongo, Bunkyo-ku, Tokyo 1130033, Japan. E-mail: yasunagah-tky@umin.ac.jp. Reprint requests: Yusuke Sasabuchi MD, Department of Clinical Epidemiology and Health Economics, School of Public Health, University of Tokyo, 7-3-1, Hongo, Bunkyo-ku, Tokyo 1130033, Japan. E-mail: sasabuchi-tky@umin.ac.jp.
}

DOI: $10.4187 /$ respcare. 03694 
prevalence of obesity is estimated to be increasing in the in-patient population, including the critically ill.

Obesity has been associated with increased mortality in the general population, ${ }^{6-8}$ whereas an inverse relationship between obesity and mortality has been reported in certain groups of hospitalized subjects. ${ }^{9-11}$ Some investigators have referred to this inverse relationship between body mass index (BMI) and mortality as the obesity paradox. However, the impact of obesity on outcomes in patients admitted to the ICU has not been definitively determined. Although 3 meta-analyses ${ }^{12-14}$ regarding the impact of obesity on outcomes in critically ill subjects showed that obesity might exert a favorable effect on mortality, definitive

See the Related Editorial on Page 1083

conclusions have not been available due to statistical heterogeneity. A recent Dutch study ${ }^{15}$ including $>150,000$ subjects demonstrated a paradoxical relationship, with a higher BMI associated with a lower mortality in critically ill subjects. However, it was not precisely analyzed which subgroup of subjects was most affected. Regarding mechanically ventilated patients, some investigators suggested that a higher BMI was associated with lower mortality, ${ }^{16,17}$ and others reported that the differences were insignificant. ${ }^{18-20}$ These discrepancies may be due to differences in the patient population or the definition of obesity between the studies. It is critical to comprehensively analyze patients admitted to the ICU to elucidate the relationship between BMI and mortality in patients undergoing mechanical ventilation.

The aim of the present study is to test the hypothesis that obesity is associated with lower mortality in the ICU population by evaluating the BMI-mortality relationship in subjects with and without mechanical ventilation.

\section{Methods}

\section{Subject Data}

This study was performed at the Graduate School of Medicine (University of Tokyo, Tokyo, Japan). In-patient data were extracted from the Diagnosis Procedure Combination database, which provides (1) classification of the ICU (general ICU, pediatric ICU, stroke care unit, high care unit, and neonatal ICU) and (2) main diagnosis, preexisting comorbidities at admission, and complications during hospitalization coded with the International Classification of Diseases, Tenth Revision codes: (a) hospital identification number, (b) procedures coded with Japanese original codes, and dates when the procedures were performed, and (c) discharge status (dead or alive). In Japan, a general ICU must meet the following criteria: (d) full-

\section{QUICK LOOK}

\section{Current knowledge}

Obesity is a serious health problem worldwide associated with an increased risk of hypertension, diabetes mellitus, heart disease, and stroke. Obesity has been associated with increased mortality in the general population, whereas an inverse relationship between obesity and mortality has been reported in some hospitalized patients.

\section{What this paper contributes to our knowledge}

A high body mass index was associated with a low mortality in mechanically ventilated subjects in this retrospective review. Non-ventilated subjects showed a reverse J-shaped association between body mass index and mortality. Both ventilated and non-ventilated underweight subjects had a higher mortality rate. These results suggest an 'obesity paradox' in mechanically ventilated patients.

time coverage by an in-house physician and (e) a patientto-nurse ratio $<2$. The Diagnosis Procedure Combination database covers approximately $50 \%$ of all admissions to acute care hospitals in Japan, because hospitals participate in the Diagnosis and Procedure Combination database voluntarily. In this study, we included all adult patients discharged between July 2010 and March 2012 who had been admitted to general ICUs during their hospitalization. We excluded patients with missing height and/or weight data, or BMI $<7.5 \mathrm{~kg} / \mathrm{m}^{2}$ or $>75 \mathrm{~kg} / \mathrm{m}^{2}$.

The institutional review board of the University of Tokyo approved this study. Informed consent was waived due to the anonymous nature of the data.

\section{Background Data}

In the Diagnosis and Procedure Combination database, height and weight is recorded at the time of hospital admission. BMI was divided into 5 categories based on the World Health Organization classification of underweight $\left(<18.5 \mathrm{~kg} / \mathrm{m}^{2}\right)$, low normal weight $\left(18.5-22.9 \mathrm{~kg} / \mathrm{m}^{2}\right)$, high normal weight $\left(23.0-24.9 \mathrm{~kg} / \mathrm{m}^{2}\right)$, overweight $(25.0-$ $\left.29.9 \mathrm{~kg} / \mathrm{m}^{2}\right)$, and obese $\left(>30.0 \mathrm{~kg} / \mathrm{m}^{2}\right)$. Surgical subjects were defined as those subjects undergoing surgery on the day of ICU admission. ICU volume was defined as the number of subjects admitted to ICUs during the study periods and divided into quartiles. Mechanically ventilated subjects were defined as subjects for whom mechanical ventilation was initiated within the first $2 \mathrm{~d}$ after ICU admission. Procedures and/or therapies performed within 


\section{BMI AND MoRTALITY IN ICU SUBJECTS}

the first $2 \mathrm{~d}$ after ICU admission and counted include: (1) platelet or fresh frozen plasma transfusion, (2) plasma exchange or apheresis, (3) catecholamine administration, (4) renal replacement therapy, (5) intra-aortic balloon pump placement, or (6) extracorporeal membranous oxygenation. The Japan coma scale at the time of hospital admission was used to describe the level of consciousness $($ Japan coma scale $0=$ alert; 1 -digit $=$ not fully alert but awake without any stimuli; 2 -digit $=$ aroused by some stimuli; 3-digit $=$ coma). ${ }^{21}$ ICU and hospital lengths of stay were calculated for subjects who survived the hospitalization.

We subsequently performed subset analyses focusing on the mechanically ventilated group and compared the mortality between the groups with and without mechanical ventilation initiated within the first $2 \mathrm{~d}$ after ICU admission.

\section{Statistical Analysis}

Continuous variables are presented as the mean $\pm \mathrm{SD}$ or the median with the interquartile range in parentheses. Categorical variables are presented as a percentage. Differences in variables between BMI categories were compared using Kruskal-Wallis tests and chi-square tests as appropriate. The dose-response relationship between inhospital mortality and BMI was calculated using a restricted cubic spline function fitted for a logistic regression model after testing the overall association and linearity using the percentage RCS Reg SAS macro developed by Desquilbet and Mariotti. ${ }^{22}$ Odds ratios and 95\% CI were calculated for BMI values with respect to the reference value of $23.0 \mathrm{~kg} / \mathrm{m}^{2}$ after controlling simultaneously for all potential confounding factors. To adjust for clustering within hospitals, generalized estimating equations ${ }^{23}$ were used. We performed separate analyses of subjects with and without mechanical ventilation using different restricted cubic spline functions. $P$ values were based on 2-tailed tests, and $P<.05$ was considered statistically significant. All analyses were performed using SPSS 22 (SPSS, Chicago, Illinois) and SAS 9.3 (SAS Institute, Cary, North Carolina).

\section{Results}

During the study period, 615,064 subjects were admitted to general ICUs. Of this total group, subjects whose height and/or weight data were missing ( $n=280,461)$, and those with a BMI $<7.5 \mathrm{~kg} / \mathrm{m}^{2}$ or $>75 \mathrm{~kg} / \mathrm{m}^{2}(n=365)$, were excluded. Data for the remaining 334,238 (54.3\%) subjects were then analyzed.

A comparison of parameters for subjects included in and excluded from the study is shown in Table 1. Excluded subjects were less likely to have undergone surgery or have a malignancy, whereas they were more likely to have initially presented in a coma. ICU and in-hospital mortality rates were higher in excluded subjects.

Overall, $23.3 \%$ of 334,238 subjects underwent initiation of mechanical ventilation within the first $2 \mathrm{~d}$ after ICU admission. The median BMI of the ventilated and nonventilated groups was $22.4 \mathrm{~kg} / \mathrm{m}^{2}$ (interquartile range $20.1-24.9 \mathrm{~kg} / \mathrm{m}^{2}$ ) and $22.2 \mathrm{~kg} / \mathrm{m}^{2}$ (interquartile range $19.7-$ $24.8 \mathrm{~kg} / \mathrm{m}^{2}$ ), respectively. Table 2 shows the baseline characteristics of subjects in each BMI category stratified by the need for mechanical ventilation. As compared with the non-ventilated group, the ventilated group was less likely to have a malignancy $(P<.001)$, but more likely to have sepsis $(P<.001)$, pneumonia $(P<.001)$, or coma $(P<.001)$. The ventilated group underwent more procedures within the first $2 \mathrm{~d}$ after ICU admission compared with the non-ventilated group. Within each BMI category, obese subjects were younger, less likely to have a malignancy, and more likely to have a pulmonary embolism than those in other categories in both ventilated and nonventilated groups. In the non-ventilated group, the proportion of subjects receiving extracorporeal membrane oxygenation within the first $2 \mathrm{~d}$ after ICU admission was not significantly different among the BMI categories, whereas in the ventilated group, the proportion of subjects receiving extracorporeal membrane oxygenation increased with increasing BMI.

Crude outcomes are shown in Table 3. ICU and inhospital mortality rates were highest in the underweight group and lowest in overweight subjects for both mechanically ventilated and non-ventilated groups. ICU and hospital lengths of stay in the non-ventilated group were comparable, whereas ICU and hospital lengths of stay for ventilated subjects were longer in obese subjects.

Table 4 shows the result of a restricted cubic spline logistic regression analysis for in-hospital mortality in nonventilated and mechanically ventilated groups. In both groups, there were significant overall and non-linear associations. This indicates that BMI is significantly associated with in-hospital mortality, and the dose-response relationship was significantly non-linear after adjusting for confounding factors.

Figures 1 and 2 depict the dose-response relationship between BMI and in-hospital mortality. In the nonventilated group, restricted cubic spline curve showed inverse J-shaped association between BMI and mortality. The mortality was lowest in subjects with a BMI of approximately $24 \mathrm{~kg} / \mathrm{m}^{2}$ and significantly higher in those with both higher and lower BMIs (Fig. 1). In the mechanically ventilated group, mortality was significantly lower in those with a higher BMI with reference to a BMI of $23 \mathrm{~kg} / \mathrm{m}^{2}$ (Fig. 2). 
Table 1. Comparison of Parameters for Excluded and Included Subjects

\begin{tabular}{|c|c|c|c|c|}
\hline & Excluded & Included & Total & $P$ \\
\hline$n$ & 280,826 & 334,238 & 615,064 & \\
\hline Age (y) (median, IQR) & $70(60-78)$ & $70(60-78)$ & $70(60-78)$ & $<.001$ \\
\hline Age $(y)($ mean $\pm S D)$ & $67.4 \pm 14.7$ & $67.7 \pm 14.2$ & $67.6 \pm 14.5$ & $<.001$ \\
\hline Male $(\%)$ & 60.2 & 60.9 & 60.6 & $<.001$ \\
\hline Surgical (\%) & 51.8 & 57.6 & 55.0 & $<.001$ \\
\hline Academic hospital (\%) & 24.8 & 26.9 & 25.9 & $<.001$ \\
\hline Malignancy (\%) & 28.5 & 32.1 & 30.5 & $<.001$ \\
\hline Sepsis $(\%)$ & 4.9 & 4.7 & 4.8 & $<.001$ \\
\hline Pneumonia $(\%)$ & 6.2 & 5.9 & 6.0 & $<.001$ \\
\hline COPD $(\%)$ & 4.9 & 6.1 & 5.6 & $<.001$ \\
\hline Pulmonary embolism (\%) & 0.8 & 0.9 & 0.9 & $<.001$ \\
\hline Acute myocardial infarction (\%) & 8.6 & 8.0 & 8.3 & $<.001$ \\
\hline Stroke $(\%)$ & 12.1 & 10.9 & 11.5 & $<.001$ \\
\hline Japan coma scale & & & & $<.001$ \\
\hline 0 (alert) $(\%)$ & 82.5 & 85.1 & 83.9 & \\
\hline 1-digit (awake without any stimuli) (\%) & 7.5 & 8.0 & 7.8 & \\
\hline 2-digit (aroused by some stimuli) (\%) & 3.5 & 3.0 & 3.2 & \\
\hline 3-digit (coma) (\%) & 6.4 & 3.9 & 5.0 & \\
\hline \multicolumn{5}{|c|}{ Procedures started by the next day of ICU admission } \\
\hline Mechanical ventilation (\%) & 25.5 & 23.3 & 24.3 & $<.001$ \\
\hline $\begin{array}{l}\text { Transfusion (fresh frozen plasma/platelet } \\
\text { concentration) }(\%)\end{array}$ & 5.8 & 6.7 & 6.3 & $<.001$ \\
\hline Plasma exchange (\%) & 0.2 & 0.1 & 0.2 & $<.001$ \\
\hline Catecholamine $(\%)$ & 38.1 & 36.4 & 37.2 & $<.001$ \\
\hline Renal replacement therapy (\%) & 5.5 & 5.1 & 5.3 & $<.001$ \\
\hline Intra-aortic balloon pump (\%) & 3.8 & 3.9 & 3.9 & 62 \\
\hline Extracorporeal membrane oxygenation (\%) & 0.6 & 0.4 & 0.5 & $<.001$ \\
\hline \multicolumn{5}{|l|}{ In-hospital outcomes } \\
\hline ICU death $(\%)$ & 6.4 & 3.5 & 4.8 & $<.001$ \\
\hline Hospital death $(\%)$ & 12.0 & 8.4 & 10.0 & $<.001$ \\
\hline ICU length of stay (d) (median, IQR) & $2(1-4)$ & $2(1-4)$ & $2(1-4)$ & $<.001$ \\
\hline Hospital length of stay (d) (median, IQR) & $23(14-38)$ & $21(14-36)$ & $22(14-37)$ & $<.001$ \\
\hline
\end{tabular}

\section{Discussion}

In this study, using a nationwide in-patient database, the restricted cubic spline curve for the mechanically ventilated group showed lower mortality in subjects with a higher BMI. In the non-ventilated group, we observed a reverse J-shaped association between BMI and mortality. There was a higher mortality rate in underweight and overweight subjects, whereas the lowest mortality was observed in the normal weight group.

To our knowledge, no previous study has examined the relationship between BMI and mortality, comparing mechanically ventilated patients and non-ventilated patients. In the present study, it is notable that a lower mortality rate is observed in higher BMI subjects only among the mechanically ventilated group. Previous reports investigating the association between BMI and mortality in mechani- cally ventilated patients show inconsistent results. ${ }^{16-20}$ These results must be interpreted with caution. A comparison of non-obese and morbidly obese mechanically ventilated subjects showed similar mortality in both groups. ${ }^{18}$ Because overweight and mildly obese subjects were excluded in a previous report, ${ }^{18}$ the results of that report cannot be compared with these results. In another report, ${ }^{16}$ underweight subjects were incorporated into the normalweight group. Because underweight subjects have been reported to have a higher mortality than normal-weight subjects in the ICU, ${ }^{15,24-29}$ combining underweight and normal-weight patients into one category may bias the results. Another report included only 807 subjects, ${ }^{19}$ which might not be a sufficient sample size to detect differences in outcomes between different BMI categories. Four of these reports ${ }^{16,17,19,20}$ restricted the study population to subjects with acute lung injury and ARDS. 


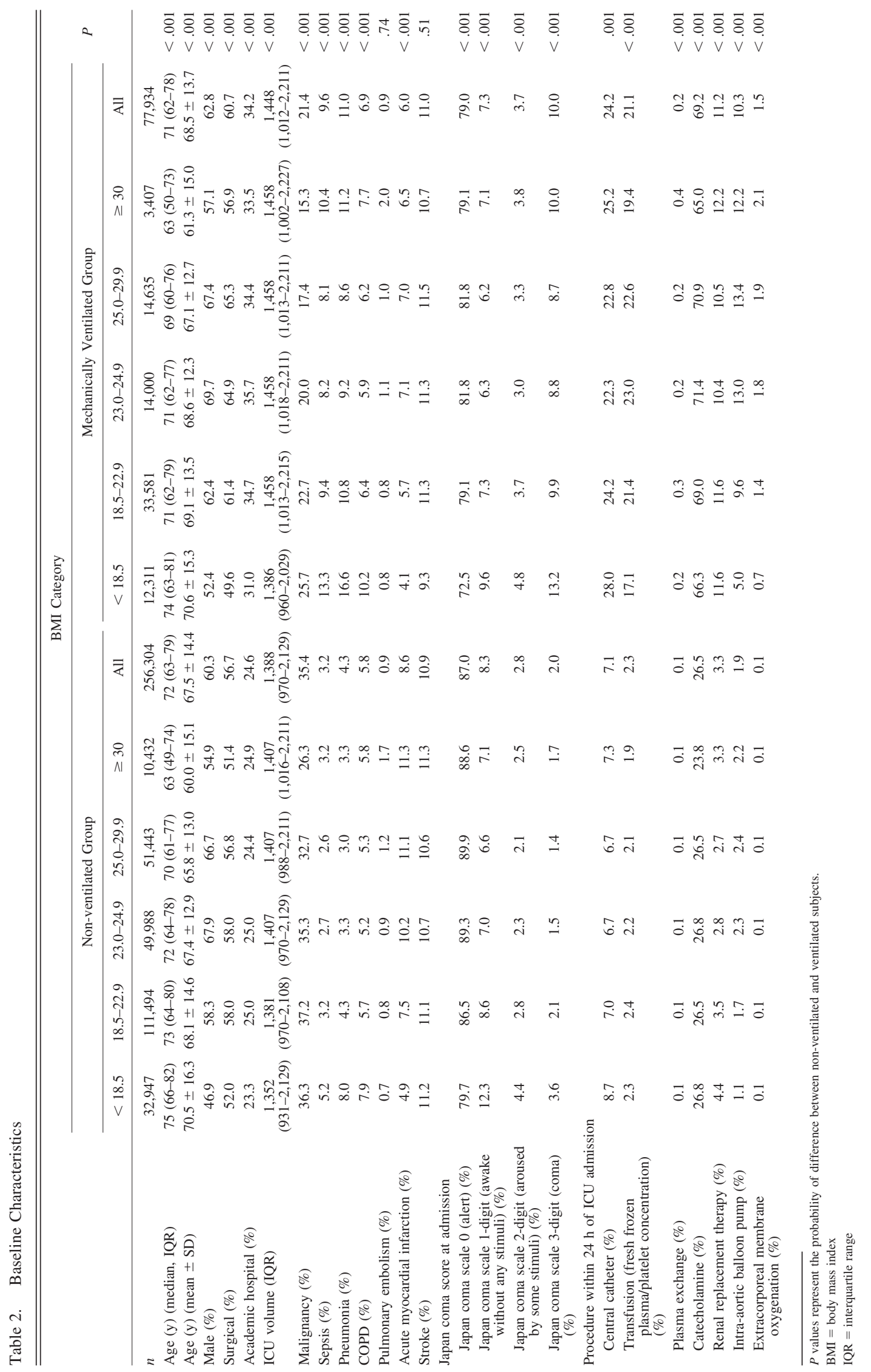




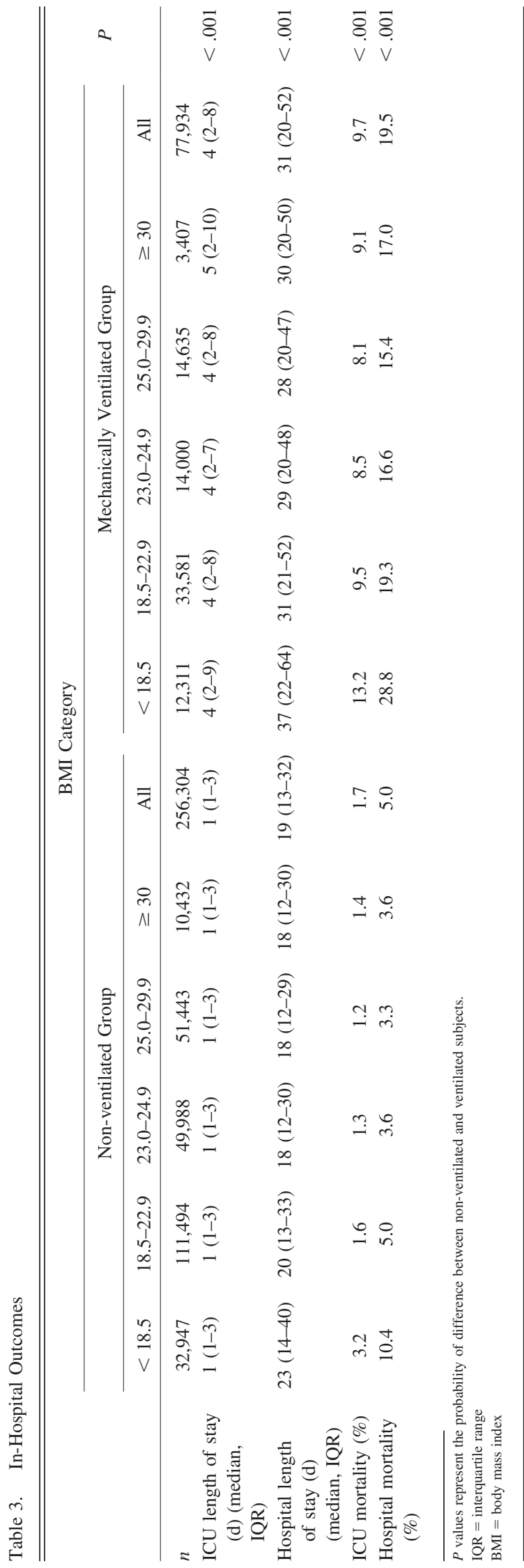

In contrast to these previous studies, the present study includes all types of ICU subjects, which may be generalizable to other populations.

Several possible explanations for the disparity in the relationship between mortality rates and BMI in ventilated and non-ventilated patients have been suggested. First, mechanical ventilation can lead to an increase in lung inflammatory cytokines, ${ }^{30}$ whereas adipose tissue plays a protective role by secreting anti-inflammatory adipokines such as leptin. ${ }^{31}$ It is suggested that higher levels of anti-inflammatory adipokines in obese patients may contribute to protection from ventilator-induced lung injury. However, patients without an underlying reason for increased levels of pro-inflammatory mediators, such as non-ventilated patients, may not benefit from higher levels of adipokines. Second, obese patients may have been intubated earlier because of their body habitus rather than the severity of their illness. 32,33 Third, the care given to obese patients may be different from normal- or under-weight patients. For example, obese patients may be more carefully observed and treated. ${ }^{13}$

In the present study, the proportion of subjects who underwent central venous catheterization is higher in obese subjects (Table 2). It is speculated that central venous catheters were placed in these subjects because of difficulties in obtaining adequate peripheral venous access in obese subjects. However, a previous report suggested an increased rate of complications due to central venous catheters in obese subjects such as catheter-related blood stream infection, ${ }^{34}$ or difficulties in central venous catheter insertion..$^{35}$ Although we could not identify complications associated with catheter insertion in this study, the percentage of subjects with indwelling central venous catheters may have biased the results to obscure a possible beneficial effect of obesity.

In the present study, ICU and hospital lengths of stay are longer in ventilated obese subjects. This finding is similar to that reported in previous studies. ${ }^{20,29,36,37}$ Most previous studies were consistent in that underweight subjects were more likely to die. ${ }^{15,24-29}$ The underweight group may include more patients with advanced malignancies or severe COPD, which could explain an association between being underweight and worse outcomes. Another possible explanation is that lean patients are less tolerant of a highly catabolic state because they have less adipose tissue. ${ }^{31}$

The present study has some limitations. In this analysis, approximately $45 \%$ of subjects were excluded due to missing BMI data. Subjects who were moribund may have been more likely to have the BMI data omitted. In fact, differences between subjects included in and excluded from the analysis may influence the effect of BMI on mortality (Table 1).

The mortality rate in this study is relatively low compared with previous reports investigating the obesity paradox. ${ }^{38,39}$ However, the mortality rate in some multicenter studies, which included various types of ICU 


\section{BMI AND MoRTALITY IN ICU SUBJECTS}

Table 4. Restricted Cubic Spline Logistic Regression Analyses of In-Hospital Mortality in Groups With and Without Ventilation

\begin{tabular}{|c|c|c|c|c|c|c|}
\hline & \multicolumn{3}{|c|}{ Non-ventilated Group } & \multicolumn{3}{|c|}{ Mechanically Ventilated Group } \\
\hline & Odds Ratio & $95 \% \mathrm{CI}$ & $P$ & Odds Ratio & $95 \% \mathrm{CI}$ & $P$ \\
\hline Academic hospital & 0.71 & $0.62-0.81$ & $<.001$ & 0.94 & $0.84-1.04$ & .22 \\
\hline Hospital volume & 0.93 & $0.87-0.99$ & .016 & 0.91 & $0.86-0.95$ & $<.001$ \\
\hline Age by $10 \mathrm{y}$ & 1.26 & $1.23-1.28$ & $<.001$ & 1.42 & $1.38-1.46$ & $<.001$ \\
\hline Sex & 0.94 & $0.89-0.98$ & .004 & 13.98 & $9.30-21.02$ & $<.001$ \\
\hline Surgical & 0.17 & $0.16-0.19$ & $<.001$ & 2.30 & $2.13-2.47$ & $<.001$ \\
\hline Malignancy & 1.95 & $1.80-2.11$ & $<.001$ & 5.29 & $4.86-5.75$ & $<.001$ \\
\hline Sepsis & 3.01 & $2.77-3.28$ & $<.001$ & 2.84 & $2.65-3.05$ & $<.001$ \\
\hline Pneumonia & 1.27 & $1.18-1.38$ & $<.001$ & 0.96 & $0.88-1.05$ & .38 \\
\hline COPD & 0.74 & $0.68-0.81$ & $<.001$ & 1.59 & $1.32-1.91$ & $<.001$ \\
\hline Pulmonary embolism & 1.43 & $1.16-1.76$ & $<.001$ & 1.48 & $1.34-1.62$ & $<.001$ \\
\hline Acute myocardial infarction & 0.93 & $0.84-1.02$ & .11 & 0.87 & $0.80-0.95$ & .003 \\
\hline Stroke & 2.12 & $1.93-2.32$ & $<.001$ & 0.25 & $0.23-0.28$ & $<.001$ \\
\hline Japan coma scale 1-digit & 1.19 & $1.08-1.31$ & $<.001$ & 2.69 & $2.40-3.01$ & $<.001$ \\
\hline Japan coma scale 2-digit & 1.32 & $1.17-1.47$ & $<.001$ & 6.54 & $4.42-9.69$ & $<.001$ \\
\hline Japan coma scale 3-digit & 3.12 & $2.81-3.46$ & $<.001$ & 1.45 & $1.26-1.67$ & $<.001$ \\
\hline $\begin{array}{l}\text { Transfusion (fresh frozen plasma/platelet } \\
\text { concentration) }\end{array}$ & 1.42 & $1.30-1.56$ & $<.001$ & 1.72 & $1.62-1.82$ & $<.001$ \\
\hline Plasma exchange & 3.18 & $2.18-4.63$ & $<.001$ & 3.15 & $2.88-3.45$ & $<.001$ \\
\hline Catecholamine & 2.07 & $1.93-2.22$ & $<.001$ & 0.82 & $0.79-0.86$ & $<.001$ \\
\hline Renal replacement therapy & 2.98 & $2.78-3.19$ & $<.001$ & 1.53 & $1.42-1.66$ & $<.001$ \\
\hline Intra-aortic balloon pump & 0.78 & $0.71-0.87$ & $<.001$ & 2.05 & $1.85-2.27$ & $<.001$ \\
\hline Extracorporeal membrane oxygenation & 4.33 & $3.53-5.31$ & $<.001$ & 5.66 & $5.01-6.40$ & $<.001$ \\
\hline Overall association (chi square) & NA & 245.7 & $<.001$ & NA & 645.6 & $<.001$ \\
\hline Nonlinear association (chi square) & NA & 244.6 & $<.001$ & NA & 333.0 & $<.001$ \\
\hline
\end{tabular}

$\mathrm{NA}=$ not applicable

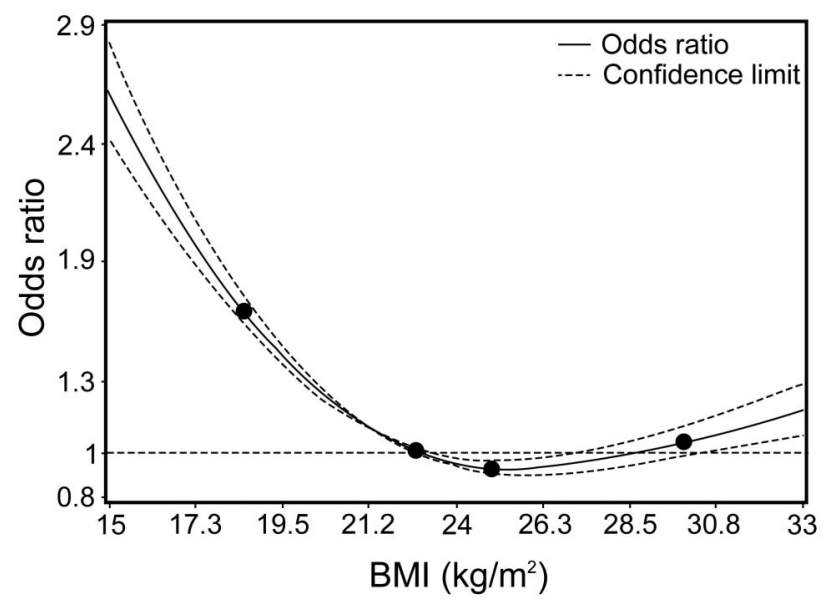

Fig. 1. Adjusted dose-response relationship between body mass index (BMI) $\left(\mathrm{kg} / \mathrm{m}^{2}\right)$ and in-hospital mortality in the non-ventilated group. The dose-response relationship is presented using a restricted cubic spline curve with 4 knots shown as points (BMI 18.5, 23.0, 25.0 , and $30.0 \mathrm{~kg} / \mathrm{m}^{2}$ ). Estimate with a $95 \% \mathrm{Cl}$ with reference to a BMI of $23 \mathrm{~kg} / \mathrm{m}^{2}$ is shown.

subjects, was comparable to that in the present study. ${ }^{40,41}$ Subjects included in these other studies and in this study may have included monitored subjects.

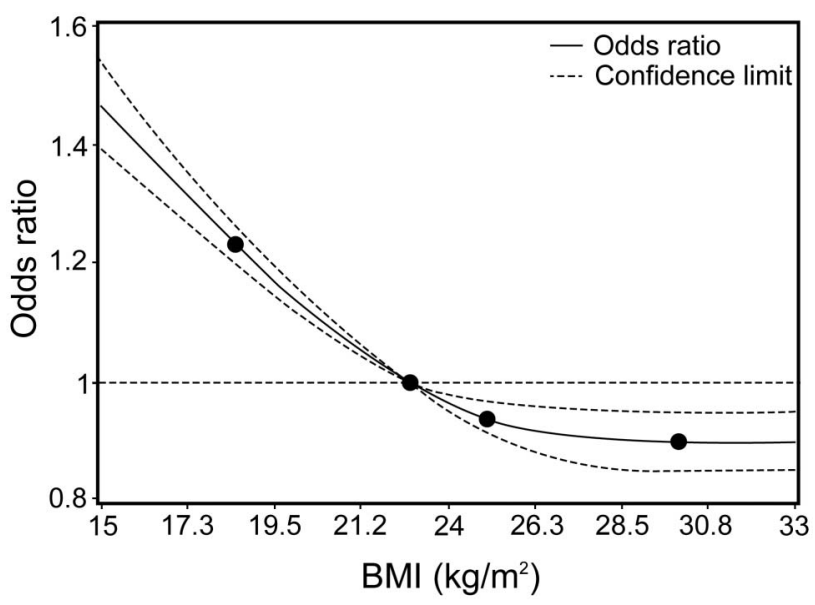

Fig. 2. Adjusted dose-response relationship between body mass index (BMI) $\left(\mathrm{kg} / \mathrm{m}^{2}\right)$ and in-hospital mortality in the mechanically ventilated group. The dose-response relationship is presented using a restricted cubic spline curve with 4 knots shown as points (BMI 18.5, 23.0, 25.0, and $30.0 \mathrm{~kg} / \mathrm{m}^{2}$ ). Estimate with a $95 \% \mathrm{Cl}$ with reference to a BMI of $23 \mathrm{~kg} / \mathrm{m}^{2}$ is shown.

The database lacks information from several commonly used scoring systems such as the APACHE (Acute Physiology and Chronic Health Evaluation) II score ${ }^{42}$ or the 


\section{BMI AND MORTALITY IN ICU SUBJECTS}

SOFA (Sequential Organ Failure Assessment). ${ }^{43}$ These scoring systems may overestimate the severity of illness in obese patients because obese patients usually have worse oxygenation than lean patients due to their physiology rather than the severity of their illness. ${ }^{44}$ Finally, the effect of unmeasured confounding factors is difficult to exclude because of the retrospective nature of this study.

\section{Conclusions}

High BMI is associated with low mortality in the mechanically ventilated group, whereas the non-ventilated group showed a reverse J-shaped association. Underweight subjects in both the mechanically ventilated and non-ventilated groups had a higher mortality rate. These results suggest that the status of being critically ill requiring mechanical ventilation is related to the mechanism of the obesity paradox.

\section{REFERENCES}

1. Caballero B. The global epidemic of obesity: an overview. Epidemiol Rev 2007;29:1-5.

2. Obesity: preventing and managing the global epidemic. Report of a WHO consultation. World Health Organ Tech Rep Ser 2000;894: i-xii, 1-253.

3. Field AE, Coakley EH, Must A, Spadano JL, Laird N, Dietz WH, et al. Impact of overweight on the risk of developing common chronic diseases during a 10-year period. Arch Intern Med 2001;161(13): 1581-1586

4. Bergström A, Pisani P, Tenet V, Wolk A, Adami HO. Overweight as an avoidable cause of cancer in Europe. Int J Cancer 2001;91(3): 421-430.

5. Calle EE, Rodriguez C, Walker-Thurmond K, Thun MJ. Overweight, obesity, and mortality from cancer in a prospectively studied cohort of U.S. adults. N Engl J Med 2003;348(17):1625-1638.

6. Adams KF, Schatzkin A, Harris TB, Kipnis V, Mouw T, BallardBarbash R, et al. Overweight, obesity, and mortality in a large prospective cohort of persons 50 to 71 years old. N Engl J Med 2006; 355(8):763-778

7. Jee SH, Sull JW, Park J, Lee SY, Ohrr H, Guallar E, Samet JM Body-mass index and mortality in Korean men and women. N Engl J Med 2006;355(8):779-787.

8. Sasazuki S, Inoue M, Tsuji I, Sugawara Y, Tamakoshi A, Matsuo K, et al. Body mass index and mortality from all causes and major causes in Japanese: results of a pooled analysis of 7 large-scale cohort studies. J Epidemiol 2011;21(6):417-430.

9. Horwich TB, Fonarow GC, Hamilton MA, MacLellan WR, Woo MA, Tillisch JH. The relationship between obesity and mortality in patients with heart failure. J Am Coll Cardiol 2001;38(3): 789-795.

10. Romero-Corral A, Montori VM, Somers VK, Korinek J, Thomas RJ, Allison TG, et al. Association of bodyweight with total mortality and with cardiovascular events in coronary artery disease: a systematic review of cohort studies. Lancet 2006;368(9536):666-678.

11. Kim BJ, Lee SH, Jung KH, Yu KH, Lee BC, Roh JK, for Korean Stroke Registry investigators. Dynamics of obesity paradox after stroke, related to time from onset, age, and causes of death. Neurology 2012;79(9):856-863.
12. Oliveros H, Villamor E. Obesity and mortality in critically ill adults: a systematic review and meta-analysis. Obesity 2008;16(3):515521.

13. Akinnusi ME, Pineda LA, El Solh AA. Effect of obesity on intensive care morbidity and mortality: a meta-analysis. Crit Care Med 2008; 36(1):151-158.

14. Hogue CW Jr, Stearns JD, Colantuoni E, Robinson KA, Stierer T, Mitter N, et al. The impact of obesity on outcomes after critical illness: a meta-analysis. Intensive Care Med 2009;35(7):11521170 .

15. Pickkers P, de Keizer N, Dusseljee J, Weerheijm D, van der Hoeven JG, Peek N. Body mass index is associated with hospital mortality in critically ill patients: an observational cohort study. Crit Care Med 2013;41(8):1878-1883.

16. O’Brien JM Jr, Philips GS, Ali NA, Aberegg SK, Marsh CB, Lemeshow $\mathrm{S}$. The association between body mass index, processes of care, and outcomes from mechanical ventilation: a prospective cohort study. Crit Care Med 2012;40(5):1456-1463.

17. O'Brien JM, Phillips GS, Ali NA, Lucarelli M, Marsh CB, Lemeshow S. Body mass index is independently associated with hospital mortality in mechanically ventilated adults with acute lung injury. Crit Care Med 2006;34(3):738-744.

18. Kumar G, Majumdar T, Jacobs ER, Danesh V, Dagar G, Deshmukh A, et al. Outcomes of morbidly obese patients receiving invasive mechanical ventilation: a nationwide analysis. Chest 2013;144(1): 48-54.

19. O’Brien JM Jr, Welsh CH, Fish RH, Ancukiewicz M, Kramer AM, National Heart L, et al. Excess body weight is not independently associated with outcome in mechanically ventilated patients with acute lung injury. Ann Intern Med 2004;140(5):338345

20. Morris AE, Stapleton RD, Rubenfeld GD, Hudson LD, Caldwell E, Steinberg KP. The association between body mass index and clinical outcomes in acute lung injury. Chest 2007;131(2):342348.

21. Shigemori M, Abe T, Aruga T, Ogawa T, Okudera H, Ono J, et al. Guidelines for the management of severe head injury, 2nd edition guidelines from the Guidelines Committee on the Management of Severe Head Injury, the Japan Society of Neurotraumatology. Neurol Med Chir 2012;52(1):1-30.

22. Desquilbet L, Mariotti F. Dose-response analyses using restricted cubic spline functions in public health research. Stat Med 2010; 29(9): 1037-1057.

23. Hanley JA, Negassa A, Edwardes MD, Forrester JE. Statistical analysis of correlated data using generalized estimating equations: an orientation. Am J Epidemiol 2003;157(4):364-375.

24. Druml W, Metnitz B, Schaden E, Bauer P, Metnitz PG. Impact of body mass on incidence and prognosis of acute kidney injury requiring renal replacement therapy. Intensive Care Med 2010;36(7):12211228

25. Engel AM, McDonough S, Smith JM. Does an obese body mass index affect hospital outcomes after coronary artery bypass graft surgery? Ann Thorac Surg 2009;88(6):1793-1800.

26. Mullen JT, Moorman DW, Davenport DL. The obesity paradox: body mass index and outcomes in patients undergoing nonbariatric general surgery. Ann Surg 2009;250(1):166-172.

27. Garrouste-Orgeas M, Troché G, Azoulay E, Caubel A, de Lassence A, Cheval C, et al. Body mass index: an additional prognostic factor in ICU patients. Intensive Care Med 2004;30(3):437-443.

28. Tremblay A, Bandi V. Impact of body mass index on outcomes following critical care. Chest 2003;123(4):1202-1207.

29. Finkielman JD, Gajic O, Afessa B. Underweight is independently associated with mortality in post-operative and non-operative pa- 


\section{BMI AND MoRTALITY IN ICU SUBJECTS}

tients admitted to the intensive care unit: a retrospective study. BMC Emerg Med 2004;4(1):3.

30. Halbertsma FJ, Vaneker M, Scheffer GJ, van der Hoeven JG. Cytokines and biotrauma in ventilator-induced lung injury: a critical review of the literature. Neth J Med 2005;63(10):382-392.

31. Pelleymounter MA, Cullen MJ, Baker MB, Hecht R, Winters D, Boone T, Collins F. Effects of the obese gene product on body weight regulation in ob/ob mice. Science 1995;269(5223):540543.

32. Littleton SW. Impact of obesity on respiratory function. Respirology 2012;17(1):43-49.

33. Ladosky W, Botelho MA, Albuquerque JP Jr. Chest mechanics in morbidly obese non-hypoventilated patients. Respir Med 2001;95(4): 281-286.

34. Dossett LA, Dageforde LA, Swenson BR, Metzger R, Bonatti H, Sawyer RG, et al. Obesity and site-specific nosocomial infection risk in the intensive care unit. Surg Infect 2009;10(2):137-142.

35. Gilbert TB, Seneff MG, Becker RB. Facilitation of internal jugular venous cannulation using an audio-guided Doppler ultrasound vascular access device: results from a prospective, dual-center, randomized, crossover clinical study. Criti Care Med 1995;23(1):60-65.

36. El-Solh A, Sikka P, Bozkanat E, Jaafar W, Davies J. Morbid obesity in the medical ICU. Chest 2001;120(6):1989-1997.

37. Bochicchio GV, Joshi M, Bochicchio K, Nehman S, Tracy JK, Scalea TM. Impact of obesity in the critically ill trauma patient: a prospective study. J Am Coll Surg 2006;203(4):533-538.
38. Shahin J, Harrison DA, Rowan KM. Relation between volume and outcome for patients with severe sepsis in United Kingdom: retrospective cohort study. BMJ 2012;344:e3394.

39. Kahn JM, Goss CH, Heagerty PJ, Kramer AA, O'Brien CR, Rubenfeld GD. Hospital volume and the outcomes of mechanical ventilation. N Engl J Med 2006;355(1):41-50.

40. Casaer MP, Mesotten D, Hermans G, Wouters PJ, Schetz M, Meyfroidt $\mathrm{G}$, et al. Early versus late parenteral nutrition in critically ill adults. N Engl J Med 2011;365(6):506-517.

41. Wallace DJ, Angus DC, Barnato AE, Kramer AA, Kahn JM. Nighttime intensivist staffing and mortality among critically ill patients. N Engl J Med 2012;366(22):2093-2101.

42. Knaus WA, Draper EA, Wagner DP, Zimmerman JE. APACHE II: a severity of disease classification system. Crit Care Med 1985; 13(10):818-829.

43. Vincent JL, de Mendonca A, Cantraine F, Moreno R, Takala J, Suter $\mathrm{PM}$, et al. Use of the SOFA score to assess the incidence of organ dysfunction/failure in intensive care units: results of a multicenter, prospective study; working group on "sepsis-related problems" of the European Society of Intensive Care Medicine. Crit Care Med 1998;26(11):1793-1800.

44. Arabi YM, Dara SI, Tamim HM, Rishu AH, Bouchama A, Khedr MK, et al. Clinical characteristics, sepsis interventions and outcomes in the obese patients with septic shock: an international multicenter cohort study. Crit Care 2013;17(2):R72.

This article is approved for Continuing Respiratory Care Education credit. For information and to obtain your CRCE

(free to AARC members) visit www.rcjournal.com

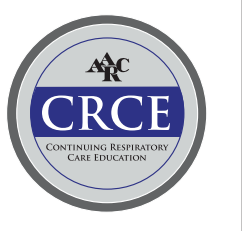

